\title{
Análise das características de uma instituição positiva de atendimento às vítimas de acidentes de trânsito
}

\author{
Analysis of the characteristics of a positive institution that assist victims of traffic accidents \\ Análisis de las características de una institución positiva de asistencia a víctimas de accidentes de \\ tráfico
}

Recebido: 20/03/2021 | Revisado: 01/04/2021 | Aceito: 03/04/2021 | Publicado: 14/04/2021

Érika Guimarães Soares de Azevedo Andrade
ORCID: https://orcid.org/0000-0003-4816-9393
Universidade Salgado de Oliveira, Brasil
E-mail: soareserika@ @ahoo.com.br
Maria Angela Mattar Yunes
ORCID: https://orcid.org/0000-00024653-3895
Universidade Salgado de Oliveira, Brasil
E-mail: mamyunes@ yahoo.com.br
Leonardo Fernandes Martins
ORCID: https://orcid.org/0000-0002-0941-6294
Universidade Salgado de Oliveira, Brasil
E-mail: leomartinsjf@gmail.com

\begin{abstract}
Resumo
O presente estudo teve como objetivo investigar características de uma instituição que desenvolve um programa de reabilitação integrada para pessoas com deficiência física e vítimas de acidentes de trânsito. A pesquisa teve como base teórica os pressupostos da Teoria Bioecológica do Desenvolvimento Humano. A Inserção Ecológica foi utilizada como recurso metodológico central num desenho qualitativo de 45 horas presenciais de visitas sistemáticas que possibilitou pesquisar: dinâmica do funcionamento institucional, valores, crenças, práticas de atendimento e resultados atingidos na percepção de profissionais e de usuários. Os princípios da teoria fundamentada nos dados nortearam as análises do material transcrito em diário de campo e de entrevistas informais realizadas em ambiente natural. Os resultados identificaram três eixos de categorias que demonstraram consistência com as características e indicadores de instituições positivas tais quais: o propósito institucional de promover empoderamento e resiliência e um projeto de cuidado físico e psicológico que enfatiza aspectos de bem-estar e de emoções positivas de todos os envolvidos no contexto de atendimento.
\end{abstract}

Palavras-chave: Rede de apoio; Resiliência; Acidente de trânsito; Instituição positiva.

\begin{abstract}
The present study aimed to investigate an institution that develops an integrated rehabilitation program for people with physical disabilities, including victims of traffic accidents. The research was based on the Bioecological Theory of Human Development. The Ecological Insertion was used as a central methodology in a qualitative design of 45 hours of systematic visits that made possible to investigate: the dynamics of the institution, main values and beliefs of the workers practices and perceived results by professionals and users. The principles of grounded theory guided the analysis of transcriptions of the field diary observations and informal interviews that were part of the material collected in loco. The results identified three main categories consistent with characteristics of positive institutions, such as: the institutional purpose to promote empowerment and resilience, and a physical and psychological care project that emphasizes well-being and positive emotions of professionals and patients involved in the context.
\end{abstract}

Keywords: Support network; Resilience; Traffic accident; Positive institution.

\section{Resumen}

El presente estudio tuvo como objetivo investigar las características de una institución que desarrolla un programa de rehabilitación integral para personas con discapacidad física y víctimas de accidentes de tránsito. La investigación se basó en los supuestos teóricos de la Teoría Bioecológica del Desarrollo Humano. La Inserción Ecológica se utilizó como recurso metodológico central en un diseño cualitativo de 45 horas de visitas sistemáticas presenciales que permitieron investigar: dinámicas de funcionamiento institucional, valores, creencias, prácticas de servicio y resultados alcanzados en la percepción de profesionales y usuarios. Los principios de la teoría fundamentados en los datos guiaron el análisis del material transcrito en un diario de campo y entrevistas informales realizadas en un entorno natural. Los resultados identificaron tres ejes de categorías que demostraron congruencia con las 
características e indicadores de las instituciones positivas tales como: el propósito institucional de promover el empoderamiento y la resiliencia y un proyecto de atención física y psicológica que enfatice aspectos de bienestar y emociones positivas de todos los involucrados. en el contexto del servicio.

Palabras clave: Red de apoyo; Resiliencia; Accidente de tránsito; Institución positiva.

\section{Introdução}

Os acidentes de trânsito são acontecimentos inesperados e frequentes no mundo contemporâneo. Suas consequências por vezes são capazes de alterar estilos e contextos de vida, tanto das vítimas como de suas famílias. Trata-se de um fenômeno de graves repercussões em âmbito mundial cujos números crescem exponencialmente a cada ano. De acordo com World Health Organization (2018), as mortes por acidente de trânsito em 2018 aumentaram para 1,35 milhões. Além dos relatórios anuais, outros estudos científicos apontam que os números de vítimas gravemente lesionadas vêm aumentando. São dezenas de milhões de pessoas e famílias que têm suas vidas totalmente modificadas (Guest et al., 2016; World Health Organization, 2018). Lamentavelmente essas estatísticas são críticas no território brasileiro onde a violência no trânsito é motivo de preocupação. Desta forma, órgãos federais, tais como o Ministério da Saúde e o Ministério das Cidades, reconhecem o tema como um problema de saúde pública (Cavalcante et al., 2009; Costa \& Araújo, 2019).

Sabe-se que após o acidente, vítimas gravemente lesionadas percorrem um longo caminho na busca pela sua recuperação. Do resgate à reabilitação, o indivíduo se depara com inúmeras situações e sensações capazes de colocar em risco o seu desenvolvimento e seu senso de cidadania. Dessa forma, é importante caracterizar quais são os fatores/processos de risco e quais são os fatores/processos de proteção. Os fatores de risco em conjunto formam condições que implicam em processos que podem prejudicar e/ou ameaçar a saúde biopsicossocial e a qualidade de vida. São elementos percebidos como negativos e que ameaçam o bem-estar e a saúde física e mental de pessoas, grupos e comunidades (Yunes, 2015). Ao passo que, os fatores ou processos de proteção demonstram a possibilidade de indivíduos ou grupos em condições de risco, conseguirem se desenvolver de maneira saudável (Araujo de Morais et al., 2012). Mecanismos de proteção minimizam os riscos, reduzem as reações negativas frente à adversidade e podem modificar de forma positiva os rumos da vida do indivíduo. Ademais, propiciam atitudes de autoeficácia na realização de tarefas que são executadas com sucesso frente às crises vivenciadas (Rutter, 2012).

Mesmo diante da relevância desse tema, é notória a carência de pesquisas com foco nas experiências de adaptação positiva de indivíduos em fase de reabilitação pós-acidente (Bertisch et al., 2014). A lacuna refere-se ainda a estudos sobre a rede de instituições que atendem as vítimas nesse contexto com vistas a possibilitar o desenvolvimento positivo numa situação em que o sofrimento, as perdas são evidentes e inegáveis. Nesse aspecto e no âmbito das redes de apoio, pouco se conhece sobre instituições positivas conceitualmente definidas como: "instituições que movem indivíduos a uma direção melhor, capaz de promover cidadania, responsabilidade, nutrição, altruísmo, civilidade, moderação e tolerância" (Seligman \& Csikszentmihalyi, 2000), ou seja, espaços de intervenção e promoção de desenvolvimento positivo que possibilitam processos de resiliência. A escassa literatura concentra-se mais especificamente em instituições de ensino (Waters et al.; White \& Murray, 2015). Constata-se, portanto, a oportunidade de expandir estudos sobre instituições positivas para outros setores além das instituições educacionais. Dessa forma, poder-se-á contribuir com estudos científicos relacionados às "Instituições Positivas" como pontos importantes de redes promotoras de desenvolvimento positivo e potencializadoras de processos de resiliência em casos de situações pós-traumáticas de diferentes naturezas.

O presente estudo tem por objetivo realizar a análise de uma instituição de um município do estado do Rio de Janeiro, identificada por desenvolver um trabalho de reabilitação integrada com pessoas com deficiências físicas de diferentes naturezas dentre as quais, vítimas de acidentes de trânsito. Buscar-se-á verificar a dinâmica do funcionamento, valores e crenças, as práticas de atendimento e resultados atingidos. Ademais, buscar-se-á compreender se esse ponto da rede apresenta indicadores 
compatíveis com os pressupostos de uma instituição positiva.

Dessa forma, além de contribuir para elaborar o desenho, implementação e execução de programas de intervenção positiva para essas populações, poder-se-á oferecer subsídios para modelos de práticas de atendimento profissional com foco em emoções positivas, bem-estar e resiliência dos vitimados e de suas famílias.

Os pressupostos teóricos e metodológicos desse estudo estão pautados na abordagem bioecológica do desenvolvimento humano (ABDH) de Urie Bronfenbrenner (2011) e no movimento da Psicologia Positiva (Seligman \& Csikszentmihalyi, 2000). A ABDH compreende o desenvolvimento a partir de interações pessoais, grupais, simbólicas tanto proximais como distais. Estas se dão em múltiplos contextos e processos ao longo do tempo, o que possibilita que fenômenos, como a resiliência, sejam compreendidos de forma dinâmica, multifacetada e sistêmica (Cecconello \& Koller, 2003; Masten, 2014; Yunes, 2015; Yunes \& Szymanski, 2003). Nesse sentido, indivíduos e famílias são compreendidos a partir de relações significativas estabelecidas por processos proximais e experiências interconectadas em diferentes contextos (Bronfenbrenner, 1996, 2011)

Dessa forma, a qualidade das interações pode ser percebida como apoio em situações de dificuldades, crises ou sofrimentos e afetar de forma positiva a saúde das pessoas (Brito \& Koller, 1999). O apoio social pode ser percebido a partir de quatro dimensões distintas, que são: apoio emocional, instrumental, informal e cognitivo (King et al., 2006; Langford et al., 1997). Como dimensão a ser identificada, o apoio emocional está intimamente relacionado à percepção de acolhimento, cuidado, ajuda de alguém afetivamente disponível e significativo. Por outro lado, o apoio instrumental vincula-se a presença de práticas e atividades específicas que buscam resolver ou melhorar situações de problemas. O apoio informal está ligado a maneiras de obter informações, orientações e conselhos que auxiliam na resolução de situações de crises. Por fim, o apoio cognitivo acontece quando alguém oferece força, incentivo, ajuda, escuta propiciando no outro sensações de autoconfiança e autonomia (King et al., 2006; Langford et al., 1997).

O apoio social sob a ótica da ABDH se estabelece a partir de relações que o indivíduo desenvolve nos diferentes ambientes e se mantém ativas a partir dos vínculos estabelecidos ao longo do tempo (Juliano \& Yunes, 2014). No que se refere a rede apoio social, esta é definida por Brito e Koller (1999) como um "conjunto de sistemas e de pessoas significativas que compõem os elos de relacionamento recebidos e percebidos do indivíduo". Para a recuperação de vítimas de acidente de trânsito e de suas famílias, estudos recentes demonstraram que a presença do suporte social e da rede de atendimento é fundamental, e os resultados do estudo de Barajas e Schechinger (2018); Migliorini et al. (2019) evidenciaram que quanto mais ordenada for essa rede de apoio e atendimento, maiores serão as chances de processos de ressignificação e aumento na qualidade de vida.

A psicologia positiva, corrente que vem se consolidando desde o final dos anos 90 e iniciada contemporaneamente na voz do professor Martim Seligman, caracteriza um movimento que busca apresentar explicações científicas para questões potencialmente saudáveis relativas ao bem-estar do ser humano (Seligman \& Csikszentmihalyi, 2000). Com foco na saúde e nos aspectos e emoções positivas, é uma linha de pensamento da Psicologia que confronta afirmações e crenças da psicologia tradicional, cujas bases explicativas se pautavam em sintomas e doenças. Nesse sentido, Seligman e Csikszentmihalyi (2000) em seu célebre artigo sobre Psicologia positiva demonstram que instituições positivas buscam trabalhar com as emoções que despertem bem-estar, satisfação, autonomia, esperança, otimismo, felicidade, sabedoria, autoestima e protagonismo, ou seja, elementos que potencializam o desenvolvimento.

Tendo por base as reflexões desse cenário teórico, foi investigada uma instituição que atende pessoas com deficiências físicas, dentre elas, vítimas de acidente de trânsito. Espera-se que os resultados dessa pesquisa possam inspirar políticas públicas de atendimento e suporte psicossocial às intervenções de cunho positivo com vistas a propiciar programas de cuidado e desenvolvimento saudável dessa população que enfrenta perdas e traumas físicos e emocionais em suas vidas. 


\section{Metodologia}

Trata-se de um estudo de caso único (Yin, 2015), descritivo-exploratório, com delineamento qualitativo (Brauner \& Ferraz, 2017) que segue o modelo teórico-metodológico da Inserção Ecológica proposta por Cecconello e Koller (2003) atualizado e utilizado por diversos pesquisadores do desenvolvimento humano (Afonso et al., 2015; Araujo de Morais et al., 2016; Cecconello \& Koller, 2016, 2019; Costa et al., 2020; Koller et al., 2020; Rosa et al., 2016). Esse modelo está pautado nos conceitos e pressupostos da Teoria Bioecológica do Desenvolvimento Humano que tem como foco compreender os processos proximais e as inter-relações entre os quatro elementos-chaves e norteadores das elaborações: processo, pessoa, contexto e tempo (Bronfenbrenner, 2011; Bronfenbrenner \& Ceci, 1994). De acordo com Cecconello e Koller (2003) essa metodologia possibilita ao pesquisador realizar uma imersão no ambiente pesquisado, o que propicia o estabelecimento de vínculos e fornece uma visão clara, sistêmica e integral dos fenômenos analisados.

\subsection{Contexto da pesquisa: a Instituição $N$}

Foi investigada uma instituição (Instituição N) sem fins lucrativos, situada no estado do Rio de Janeiro. Fundada em 1981 é considerada uma das maiores entidades no trabalho junto a pessoas com deficiência física do Brasil. A pesquisa documental evidenciou que na busca pela inclusão, emprega mais de 300 pessoas com diferentes deficiências físicas/motoras a partir de convênios e parcerias com empresas públicas e privadas. Para compreender o indivíduo de maneira integral em seus diferentes contextos, suas diretrizes revelam como proposta pedagógica e social, o desenvolvimento de um programa de reabilitação integrada (PRI) e cidadã. Segundo indicam os documentos, o programa está pautado em três pilares básicos que visam a desenvolver: (a) saúde e reabilitação; (b) inclusão social, cidadania e inserção no mercado de trabalho; e (c) incentivo ao esporte. O programa foi criado com foco na promoção de saúde (fisioterapia, fonoaudiologia, terapia ocupacional), nas questões sociais (inclusão social/ orientação e apoio na busca pelos direitos e benefícios/ cidadania/ empregabilidade); e na promoção de qualidade de vida e bem-estar por meio do esporte.

Dessa maneira, essa instituição se difere das demais e foi escolhida como contexto de análise por desenvolver um trabalho que compreende o indivíduo não somente no que tange a reabilitação física, mas por oferecer práticas de atendimento e cuidado no campo social, emocional, na promoção de empregabilidade, no estímulo das práticas esportivas e na melhoria da qualidade de vida.

\subsection{Participantes}

Participaram desse estudo 7 integrantes da Instituição N: 3 funcionárias (F1, F2 e F3) e 4 pacientes (P1, P2, P3 e P4) com deficiência física vítimas de acidente de trânsito. Cinco dos participantes são do sexo feminino (3 - três da equipe profissional e 2 - duas pacientes) e 2 são do sexo masculino (pacientes da instituição). Dos quatro acidentados, 3 estavam em motocicletas e 1 em carro de passeio. Os participantes residem em 3 diferentes municípios do estado do Rio de Janeiro, possuem entre 16 e 50 anos e fazem parte das atividades da instituição há mais de três meses. O critério de inclusão utilizado no estudo era que todos os pacientes fossem vítimas de acidentes de trânsito e tivessem sequelas físicas permanentes em função do acidente.

\subsection{Instrumentos}

Os instrumentos utilizados foram a pesquisa documental, o diário de campo, observações naturalísticas, contatos informais e entrevistas abertas com todos os participantes. As entrevistas não seguiram um roteiro fixo e pré-estabelecido, mas foram pautadas de modo a possibilitar a abordagem de temáticas relacionadas à dinâmica e funcionamento da instituição. Essa ferramenta possibilitou que diálogos informais e espontâneos emergissem acerca da instituição no que tange às relações 
estabelecidas, crenças compartilhadas, experiências e percepções vivenciadas em contexto por funcionários e pacientes.

O diário de campo foi utilizado para registro das observações naturalísticas e percepções da pesquisadora. Tais observações proporcionam maior riqueza de detalhes sobre o contexto analisado, as relações proximais estabelecidas, os processos e sentimentos compartilhados durante os encontros. De acordo com Morais et al. (2016) essa ferramenta proporciona maior clareza aos dados no momento em que as análises são realizadas uma vez que retrata de forma real os sentimentos e percepções vivenciados pelo pesquisador nos diferentes momentos da pesquisa.

\subsection{Procedimento}

Esse estudo foi submetido e aprovado pelo comitê de ética através da Plataforma Brasil número 084370/2019. Foram realizados contatos telefônicos e o agendamento de uma entrevista presencial na instituição. A inserção ecológica teve início a partir da primeira visita e possibilitou ao longo dos encontros a realização de observações naturalísticas, pesquisa documental, participação em atividades e o desenvolvimento de conversas informais e formais com funcionários, pacientes e familiares. Essa metodologia possibilitou dar validade e vitalidade aos dados encontrados.

Na primeira entrevista, foi entregue o termo de Consentimento Livre e Esclarecido e realizada as explicações éticas da pesquisa, bem como o detalhamento do estudo a partir dos objetivos, metodologia para coleta de dados e possíveis contribuições que os resultados desse estudo poderiam gerar como subsídios a novas políticas públicas e melhoria na qualidade de vida da população analisada.

As visitas aconteceram nos meses de agosto a outubro de 2019, todos previamente agendados com a assistente social. Os encontros foram programados para dias que estivessem presentes, no quadro de atendimento, os pacientes lesionados por serem vítimas de acidentes de trânsito. Foram realizadas 15 visitas que aconteceram em dias da semana alternados, no turno da tarde das 14 às 17 horas, totalizando 45 horas presenciais. As observações e percepções acerca do ambiente, as relações estabelecidas, os sentimentos compartilhados, as sensações percebidas e os insights (memos) foram registrados no diário de campo a cada encontro. Esse registro buscou adicionar aos dados coletados: sensibilidade, clareza, coerência e objetividade.

No que se refere à análise de dados todas as entrevistas foram gravadas, transcritas na íntegra, lidas sistematicamente seguindo os passos da Análise Fundamentada nos Dados ou Grounded-Theory. Essa metodologia de análise de dados qualitativos, propicia ao pesquisador organizar o material coletado a partir de narrativas que possibilitam a construção de códigos, eixos, categorias e subcategorias que emergem a partir dos dados e da sistematização analítica e conceitual realizadas (Charmaz, 2009).

\section{Resultados}

Os resultados das análises das entrevistas e do diário de campo evidenciaram três eixos de análise de categorias: (a) Propósito de Empoderamento; (b) Experiências Positivas Vivenciadas; e (c) Resultados alcançados.

\subsection{Propósito de Empoderamento}

Essa categoria se destacou nas narrativas dos profissionais que evidenciaram elementos que possibilitam retratar o propósito da instituição como sendo o de promover e possibilitar o empoderamento da pessoa com deficiência. Nesse sentido, os relatos verificados nas observações naturalísticas, atestam a implementação de projetos a partir de uma compreensão global do indivíduo, proporcionando o seu engajamento em atividades sociais, laborais e esportivas. Os profissionais sublinham caminhos que a instituição percorre para propiciar o empoderamento com base em um Programa de Reabilitação Integrada (PRI) alicerçado em três pilares: (i) saúde e reabilitação física; (ii) inclusão social/empregabilidade/cidadania; e (iii) incentivo a prática de esportes/qualidade de vida, o que corresponde exatamente aos parâmetros pedagógicos presentes na documentação 
institucional.

Para os trabalhadores da instituição, o desenvolvimento do PRI propicia e faz emergir expressões de empoderamento, protagonismo, autonomia, inclusão social, empatia, criação de vínculos afetivos, autoestima, coragem, força, persistência e esperança. Tais expressões em conjunto representam as potencialidades e o propósito da instituição, demonstradas na Tabela 1.

Tabela 1. Categoria - Propósito de Empoderamento.

\begin{tabular}{|c|c|}
\hline Subcategoria & Exemplos de narrativa \\
\hline $\begin{array}{l}\text { Caminhos do } \\
\text { empoderamento }\end{array}$ & $\begin{array}{l}\text { “... É uma instituição que propicia uma reabilitação integrada (PRI), pautada na saúde, } \\
\text { cidadania/mercado de trabalho, esporte e que promove autonomia e o protagonismo do indivíduo. Esse é } \\
\text { o diferencial da Instituição N. Faço parte dessa equipe de profissionais e vejo todos os dias o quanto é } \\
\text { importante o paciente ser cuidado e apoiado nos diferentes contextos que está inserido (físico, emocional, } \\
\text { econômico, social ...). O desempenho e o resultado é outro, vai além da fisioterapia.” (F2) } \\
\text { “... O PRI é o diferencial da Instituição N em relação a outras instituições que tem como foco apenas a } \\
\text { reabilitação física. A Instituição N, tenta mostrar que esse é o começo de uma nova história, que a vida } \\
\text { terá mudanças, mas que pode ser vivida intensamente, que nós podemos ajudar e apoiar, mas que todos } \\
\text { de maneira singular são capazes de vencer.” (F1) }\end{array}$ \\
\hline $\begin{array}{l}\text { Expressões de } \\
\text { empoderamento }\end{array}$ & $\begin{array}{l}\text { “... O apoio em relação a busca de direitos/benefícios da pessoa com deficiência e a reinserção no } \\
\text { mercado de trabalho proporciona ao paciente um resgate a sua autonomia, autoestima e ao protagonismo } \\
\text { de sua vida papel muitas vezes colocado em segundo plano por essas pessoas.” (F3). } \\
\text { “... O paciente muitas vezes deposita em você o sucesso do tratamento, mas com o tempo e pelo fato da } \\
\text { reabilitação ser integrada ele percebe que somos, um meio, um apoio e que a força para mudar está } \\
\text { dentro da própria pessoa. Por isso é tão importante dar voz e incentivar a autonomia de cada pessoa com } \\
\text { deficiência que integra a nossa instituição.” (F2). }\end{array}$ \\
\hline
\end{tabular}

Fonte: Autores.

Importante ressaltar que os relatos declararam que a instituição $\mathrm{N}$ sofreu os impactos de uma crise financeira nos anos de 2016 e 2017 que afetaram a continuidade de algumas atividades oferecidas. Esse fato trouxe alguns desafios no sentido de manter a missão e o apoio integrado a todos os usuários. Mas, a despeito das adversidades, os funcionários relataram que os administradores têm procurado se adaptar às novas rotinas e buscado recursos para que os serviços e as práticas de atendimento e cuidado continuem oferecendo o mesmo sentido e qualidade a todos os seus integrantes.

\subsection{Experiências Positivas Vivenciadas}

Essa categoria busca representar as ações e expressões que movem a instituição e que podem ser percebidas a partir das experiências positivas vivenciadas, tanto por profissionais como por seus usuários. As análises desses elementos trouxeram evidências que fortalecem os propósitos de empoderamento no Programa de trabalho da instituição e se destacam por oferecer um olhar positivo e de esperança frente às situações de trauma vivenciadas. As experiências são expressas por parte dos profissionais a partir de suas práticas de atendimento/cuidado e por parte dos pacientes por meio de suas expressões e sentimentos de satisfação compartilhados ao longo do processo de reabilitação.

\subsubsection{Por parte dos funcionários: Atitudes de promoção de emoções positivas.}

De acordo com as narrativas dos profissionais, algumas práticas realizadas propiciam processos de desenvolvimento positivo que humanizam e potencializam a qualidade das relações proximais. As atitudes dos agentes geram emoções positivas como acolhimento, apoio e oferecem apoio emocional e instrumental para que a vida possa recomeçar e prosseguir. Os profissionais ressaltam a importância de promover e incentivar um olhar otimista e de esperança frente ao trauma. Para tanto, realiza-se um atendimento solidário com comunicação clara e transparente capaz de gerar confiança em relação a situação de 
cada paciente. As práticas de atendimento oferecem uma escuta cuidadosa, dialógica, com paciência e respeito ao tempo e ao limite de cada um. Propiciar o fortalecimento de vínculos afetivo, social, no grupo institucional, inclui a participação da família que tem um papel essencial no desenvolvimento da reabilitação como um todo. A positividade das experiências dos profissionais afirma a constante busca em compreender que sentimentos extremos como alegria \& tristeza, frustração \& conquistas caminham juntos. As observações demonstraram que há um trabalho ativo e constante na promoção e viabilização de eventos comemorativos, atividades artísticas, passeios a museus, festivais de música e paraolimpíadas. Adicionalmente estimula-se a prática de esportes, sobretudo para atletas de alto rendimento almejando uma integração plena no âmbito social dos atletas que representam a instituição nacional e internacionalmente. Esses elementos, verificados na Tabela 2 a partir de relatos dos profissionais, fortalecem os propósitos da instituição que se destacam por oferecer um olhar positivo e de esperança frente a situações de trauma e risco vivenciadas.

Tabela 2. Categoria - Experiências Positivas Vivenciadas (funcionários).

\begin{tabular}{ll}
\hline Subcategoria & \multicolumn{1}{c}{ Exemplos de narrativa } \\
\hline & $\begin{array}{l}\text { “... Todas as avaliações com os pacientes são realizadas de maneira transparente, ou seja, o paciente tem } \\
\text { consciência do seu estado da primeira até a última avaliação. E essas avaliações nos possibilitam ter uma } \\
\text { noção de como ele está físico e emocionalmente, a partir daí conduzimos o tratamento de maneira mais } \\
\text { orientada, fazendo a pessoa entender que ela pode progredir, ter uma qualidade de vida melhor e mais } \\
\text { autonomia.” (F2) }\end{array}$ \\
$\begin{array}{l}\text { Atitudes de } \\
\text { promoção de } \\
\text { emoções } \\
\text { positivas }\end{array}$ & $\begin{array}{l}\text { “... Buscamos propiciar um ambiente em que o convívio com a família e com outras pessoas seja } \\
\text { benéfico para todos que participam da reabilitação, essa rede propicia que o paciente sinta que não está } \\
\text { sozinho, existe uma troca de saberes, informações, amizade, socialização, alegria, força, apoio durante o } \\
\text { tratamento.”(F1) }\end{array}$ \\
\hline
\end{tabular}
Fonte: Autores.

\subsubsection{Por parte dos pacientes vítimas de acidente de trânsito: Sendo incentivados e fortalecidos social e emocionalmente.}

As falas dos pacientes demonstram que as experiências de se sentirem acolhidos, apoiados, ouvidos e respeitados como pessoas ativas são, capazes de mudar a sua realidade e os incentivam a exercer seus papéis sociais como cidadãos. Após viverem os traumas dos acidentes, algumas vezes graves, os pacientes revelam relatos com crenças que indicam elementos de força psíquica, bem-estar e autoeficácia, essenciais para a busca de um recomeço. Ademais, foi possível verificar na narrativa e nas observações das atividades dos usuários, os sentimentos de bom humor e satisfação com a sensação de estar ativo no processo de reabilitação. Esses elementos em conjuntos estimulam e propiciam comportamentos positivos de desenvolvimento pessoal que refletem no fortalecimento como ator social e na melhoria da qualidade de vida dos usuários e de suas famílias, conforme demonstrado na Tabela 3.

Tabela 3. Categoria - Experiências Positivas Vivenciadas (pacientes).

\begin{tabular}{|c|c|}
\hline Subcategoria & Exemplos de narrativa \\
\hline $\begin{array}{l}\text { Sendo } \\
\text { incentivados e } \\
\text { fortalecidos }\end{array}$ & $\begin{array}{l}\text { “... Meus parentes achavam que eu não iria voltar a caminhar, as vezes até eu achava. Cheguei aqui na } \\
\text { cadeira de rodas, não falava direito, tremia muito. Mas o pessoal da equipe me recebeu muito bem, me } \\
\text { dava esperança, dizia que eu ia ficar boa, que eu podia melhorar e que eles iam me ajudar.” (P1) }\end{array}$ \\
\hline $\begin{array}{l}\text { social e } \\
\text { emocionalmente }\end{array}$ & $\begin{array}{l}\text { “... Eu sou muito otimista e a instituição também passa isso para a gente, ninguém aqui é coitadinho todo } \\
\text { mundo tem que fazer a sua parte”. (P2) }\end{array}$ \\
\hline
\end{tabular}




\subsection{Resultados alcançados}

A satisfação e a gratidão são claros elementos manifestos pelos participantes, tanto por profissionais quanto usuários e caracterizam essa categoria. Os relatos demonstraram com unicidade que tanto funcionários quanto pacientes manifestam engajamento e o sentimento de pertencimento à instituição. Integrar a instituição é motivo de orgulho para as duas classes: profissionais e pacientes. Essa sensação de unidade, colaboração mútua e satisfação foram expressões compartilhadas por todos. A inclusão social, a inserção ou reinserção no mercado de trabalho, o direito de ir e vir com autonomia demonstra que investir nas potencialidades sem desconsiderar as fraquezas, resulta em melhorias diárias e contínuas promotoras de felicidade percebida por todos e todas. A maioria dos relatos enfatiza que a reabilitação a partir do esporte resulta na eficácia de um trabalho desenvolvido em conjunto que propicia superação, eleva a autoestima, promove autonomia e bem-estar. Em comum, é relatado o orgulho de estar e ser parte da instituição, identificados a partir de relados na Tabela 4.

Tabela 4. Categoria - Resultados Alcançados.

\begin{tabular}{ll}
\hline Subcategoria & \multicolumn{1}{c}{ Exemplos de narrativa } \\
\hline & $\begin{array}{l}\text { “... Eu indico a instituição para todo mundo que posso, aqui é muito além de uma fisioterapia, tem inclusão } \\
\text { social, você está no meio das pessoas que sentem o que você sente, aqui é uma segunda família. A gente } \\
\text { briga se desculpa se abraça. Isso aqui me faz muito bem, sou muito grata. Aqui a gente faz acontecer.” (P3) }\end{array}$ \\
$\begin{array}{l}\text { Orgulho e } \\
\text { satisfação } \\
\text { (funcionários } \\
\text { e pacientes) }\end{array}$ & $\begin{array}{l}\text { “... Muitos pacientes que participam da reabilitação integrada, hoje estão no projeto da dança profissional, } \\
\text { incluídos no mercado de trabalho, alguns fazem parte do time de atletas de alto rendimento e representam a } \\
\text { instituição em eventos nacionais e internacionais. Potencialmente exercem um papel de cidadania com } \\
\text { maior autonomia e com um olhar positivo em relação a realidade vivenciada. Tenho muito orgulho de } \\
\text { participar de tudo isso.” (F1) }\end{array}$ \\
\hline
\end{tabular}

Fonte: Autores.

\section{Discussão}

O foco desse estudo foi analisar uma instituição que desenvolve um programa de atividades com pessoas portadoras de deficiências físicas. Mantendo o objetivo de investigar o trabalho realizado com vítimas de acidentes no trânsito, buscou-se verificar como a instituição organiza seu funcionamento, suas crenças, práticas de atendimento/cuidado e os resultados alcançados. A partir das lentes da Bioecologia do Desenvolvimento Humano (Bronfenbrenner, 2011) e dos conceitos pilares da psicologia positiva (Seligman \& Csikszentmihalyi, 2000), pode-se compreender alguns indicadores desse ambiente ecológico que caracterizam uma instituição positiva, promotora de desenvolvimento saudável e de processos de resiliência.

A associação da metodologia de inserção ecológica com a análise de acordo com os princípios da teoria fundamentada nos dados possibilitou a identificação de três eixos temáticos elucidativos dos movimentos cotidianos do trabalho realizado pela instituição pesquisada: propósito de empoderamento, experiências positivas vivenciadas e resultados alcançados. Essas categorias em conjunto, o propósito de empoderamento, as experiencias positivas vivenciadas por funcionários e pacientes e os resultados satisfatórios alcançados demonstraram que a instituição funciona como rede de apoio. As características analisadas em detalhes nas subcategorias são consistentes com o conceito de instituição positiva (Seligman \& Csikszentmihalyi, 2000), tendo em vista a constatação de relatos comuns de empoderamento a partir de uma reabilitação integrada com foco nos aspectos salutogênicos e no desenvolvimento das emoções positivas.

As categorias de análise do presente estudo evidenciaram um microssistema onde a força dos vínculos é nutrida no cotidiano. Os laços afetivos tornam-se elementos ativos capazes de propiciar um sentido positivo aos pacientes que buscam recuperação de um trauma que advém da perda de habilidades e de movimentação física após o acidente. Nesse cenário, a qualidade nas relações proximais e suas propriedades de reciprocidade, afeto e equilíbrio de poder (Bronfenbrenner, 1996) são 
fundamentais.

De acordo com os princípios da análise fundamentada nos dados, as categorias do estudo se conectam e contam a história de uma instituição positiva. Como um ponto da rede de apoio à pessoa com deficiência física, a instituição funciona como uma unidade que percorre um caminho de atividades e um sistema de crenças pautado no empoderamento e da autonomia. O desenvolvimento da reabilitação integrada, que descreve o propósito da instituição, valoriza e propicia um trabalho com foco nos aspectos da saúde física e mental, inclusão social, protagonismo, cidadania e qualidade de vida. O protagonismo estimulado possibilita a autonomia, a autoestima, a coragem e promove sentimentos de felicidade e bem-estar, o que é uma conquista para pessoas que viveram situações de risco de dor e sofrimento. A junção dessas categorias dialoga com o movimento da psicologia positiva que tem como tema o bem-estar e como premissa fortalecer as competências ao invés de corrigir e focar deficiências (Seligman \& Csikszentmihalyi, 2000). Os resultados indicaram que essa instituição é um ponto de apoio emocional e instrumental na vida dos usuários e os move na direção de desenvolver novas competências físicas, sociais, emocionais a partir de incentivo de emoções positivas e de sentido de esperança frente as dificuldades da vida. As práticas de atendimento e cuidado baseadas em acolhimento, amor e engajamento profissional propiciam experiencias de encorajamento, bom humor e alegria. Mais uma vez, tais resultados convergem para a definição de instituições positivas introduzidas por Seligman e Csikszentmihalyi (2000); Waters et al. (2012); White e Murray (2015). Essa constatação indica a potência que princípios de instituições positivas podem ter como norteadores de redes de apoio. É fato que se deve investir no papel destas entidades como promotoras de desenvolvimento e ativadoras de processos de resiliência em contextos de adversidades pessoais e grupais (Yunes \& Juliano, 2015; Zappe et al., 2015).

A satisfação e a gratidão descritas na categoria que destaca os resultados alcançados pelo trabalho institucional evidenciam a importância de mecanismos de proteção em situação de dor de tal complexidade. Esses achados corroboram com estudos realizados por Juliano e Yunes (2014) que demonstram a importância das redes de apoio como elemento de proteção capazes de ativar processos de resiliência. Pesquisas internacionais (Barajas \& Schechinger, 2018; Migliorini et al., 2019) focadas nas vítimas de acidentes de trânsito identificaram que quanto mais presente e ordenada for a rede de apoio e atendimento, maiores são as possibilidades de recuperação e ressignificação de sentidos de vida.

Diante disso, o presente estudo aponta conexão entre as características de instituições positivas e os processos de resiliência. De acordo com Seligman e Csikszentmihalyi (2000) essas instituições "movem indivíduos a uma direção melhor, capaz de promover cidadania, responsabilidade, nutrição, altruísmo, civilidade, moderação, tolerância" além de trabalhar intensamente com emoções positivas em prol de um desenvolvimento contínuo. No entanto, mesmo passados 20 anos dessas elaborações, ainda são poucos os estudos que tratam desse importante constructo. Tratar e promover um maior número de instituições com bases positivas pode ativar processos de resiliência e gerar bem-estar em um maior número de indivíduos e famílias que vivem situação de traumas diversos, dentre os quais destacamos as vítimas de acidentes de trânsito, de quem se tratou no presente estudo.

Uma das limitações dessa pesquisa, e um resultado inesperado, foi o número reduzido de pacientes vítimas de acidente de trânsito em tratamento na instituição no momento da pesquisa. O número mais expressivo de pacientes em tratamento na instituição pesquisada era vítima de projétil de arma de fogo (PAF). Para além disso outra limitação encontrada foi, que por ser um estudo de caso único, essa pesquisa não viabiliza comparações com outras instituições das redes de apoio e atendimento relativas a essa população.

\section{Conclusão}

A realização desse estudo possibilitou identificar uma instituição na rede de serviços de apoio, que cumpre seu papel de proteção e demonstra acreditar nas potencialidades dos seres humanos capazes de expressar seus talentos em diferentes 
situações. Reconhece a pessoa com deficiência física como protagonista de sua própria vida e capaz de começar e configurar novas histórias. Diante disso, recomenda-se novas pesquisas nessa mesma direção para contribuir com a reformulação e construção de políticas públicas que tragam investimentos em instituições potencializadoras de desenvolvimento positivo a vítimas gravemente lesionadas e suas famílias. Redes de serviços formados por instituições positivas fortalecem a saúde física e psíquica de seus usuários a partir do foco em aspectos salutogênicos que geram qualidade de vida, felicidade, resiliência e bem-estar.

É relevante que futuros estudos sejam realizados para identificar outras fontes de apoio social com características que as façam ser reconhecidas como instituições positivas em contextos distintos da área da saúde e educação. Nesse sentido, a disseminação de instituições potencializadoras de desenvolvimento positivo poderá trazer benefícios a diferentes populações que por razões diversas clamam por atenção de serviços sociais. Estudos multicasos poderiam ser realizados com instituições distintas que atendam essa população para que comparações possam ser feitas para verificar os propósitos, programas de reabilitação, as práticas utilizadas e experiências vivenciadas bem como os resultados alcançados.

\section{Referências}

Afonso, T., Silva, S. S. d. C., Pontes, F. A. R., \& Koller, S. H. (2015). O uso do diário de campo na inserção ecológica em uma família de uma comunidade ribeirinha amazônica. Psicologia \& Sociedade, 27(1), 131-141. https://doi.org/10.1590/1807-03102015v27n1p131

Araujo de Morais, N., Koller, S. H., \& Raffaelli, M. (2012). Rede de apoio, eventos estressores e mau ajustamento na vida de crianças e adolescentes em situação de vulnerabilidade social Universitas Psychologica, 11, 779-791. https://doi.org/10.11144/Javeriana.upsy11-3.raee

Araujo de Morais, N., Koller, S. H., \& Raffaelli, M. (2016). Inserção Ecológica na pesquisa sobre trajetórias de vida de adolescentes em situação de vulnerabilidade social: Identificando fatores de risco e proteção. In S. H. Koller, N. Araujo de Morais, \& S. d. S. Paludo (Eds.), Inserção ecológica: um método de estudo do desenvolvimento humano (pp. 67-94). Casa do Psicólogo.

Barajas, M. S., \& Schechinger, H. (2018). Children and youth: Resilience after motor vehicle accidents. International Journal of Child and Adolescent Health, 11(2), 235. https://psycnet.apa.org/record/2017-34564-009

Bertisch, H., Rath, J., Long, C., Ashman, T., \& Rashid, T. (2014). Positive psychology in rehabilitation medicine: A brief report. NeuroRehabilitation, 34(3), 573-585. https://doi.org/10.3233/NRE-141059

Brauner, M. C. C., \& Ferraz, D. B. (2017). Uma visão holística das práticas em saúde mental amparadas na bioética latino-americana. Cadernos IberoAmericanos De Direito Sanitário, 6(4), 10-26. https://doi.org/10.17566/ciads.v6i4.408

Brito, R. C. d., \& Koller, S. H. (1999). Desenvolvimento humano e redes de apoio social e afetivo In A. M. Carvalho (Ed.), O mundo social da criança: natureza e cultura em ação (pp. 115-129). Casa do Psicólogo.

Bronfenbrenner, U. (1996). A ecologia do desenvolvimento humano: experimentos naturais e planejados. Artes Médicas.

Bronfenbrenner, U. (2011). Bioecologia do desenvolvimento humano: tornando os seres humanos mais humanos Artmed Editora.

Bronfenbrenner, U., \& Ceci, S. J. (1994). Nature-nuture reconceptualized in developmental perspective: A bioecological model Psychological review, 101(4), 568-586. https://doi.org/10.1037/0033-295X.101.4.568

Cavalcante, F. G., Morita, P. A., \& Haddad, S. R. (2009). Sequelas invisíveis dos acidentes de trânsito: o transtorno de estresse pós-traumático como problema de saúde pública Ciência \& Saúde Coletiva, 14, 1763-1772. https://doi.org/10.1590/S1413-81232009000500017

Cecconello, A. M., \& Koller, S. H. (2003). Inserção ecológica na comunidade: uma proposta metodológica para o estudo de famílias em situação de risco Psicologia: Reflexão e Crítica, 16, n. 3, 515-524. https://doi.org/10.1590/S0102-79722003000300010

Cecconello, A. M., \& Koller, S. H. (2016). Inserção ecológica na comunidade: uma proposta metodológica para o estudo de famílias em situação de risco. In N. Araujo de Morais, S. H. Koller, \& M. Raffaelli (Eds.), Inserção ecológica: um método de estudo do desenvolvimento humano (pp. 39-64). Casa do Psicólogo.

Cecconello, A. M., \& Koller, S. H. (2019). Ecological engagement in the community: A methodological proposal for the study of families at risk In Ecological Engagement (pp. 13-27). Springer.

Charmaz, K. (2009). A construção da teoria fundamentada: guia prático para análise qualitativa. Artmed.

Costa, M. J. M. d., Yunes, M. A. M., \& Achkar, A. M. N. E. (2020). A inserção ecológica como estratégia investigativa do atendimento e cuidado de pacientes oncológicos Research, Society and Development, 9(11), e67891110067. https://doi.org/10.33448/rsd-v9i11.10067

Costa, R. N. V., \& Araújo, J. C. O. (2019). Uma análise da relação da utilização do seguro obrigatório DPVAT com o aumento da frota de veículos nacional/An analysis of the relationship of the use of compulsory DPVAT insurance to the increase of the national vehicle fleet Brazilian Journal of Development, 5(9), 15599-15611. https://doi.org/10.34117/bjdv5n9-137 
Guest, R., Tran, Y., Gopinath, B., Cameron, I. D., \& Craig, A. (2016). Psychological distress following a motor vehicle crash: a systematic review of preventative interventions Injury, 47(11), 2415-2423. https://doi.org/10.1016/j.injury.2016.09.006

Juliano, M. C. C., \& Yunes, M. A. M. (2014). Reflexões sobre rede de apoio social como mecanismo de proteção e promoção de resiliencia Ambiente \& Sociedade, 17(3). https://doi.org/10.1590/S1414-753X2014000300009

King, G., Willoughby, C., Specht, J. A., \& Brown, E. (2006). Social support processes and the adaptation of individuals with chronic disabilities Qual Health Res, 16(7), 902-925. https://doi.org/10.1177/1049732306289920

Koller, S. H., Raffaelli, M., \& de Morais, N. A. (2020). From Theory to Methodology: Using Ecological Engagement to Study Development in Context Child Development Perspectives, 14(3), 157-163. https://doi.org/10.1111/cdep.12378

Langford, C. P. H., Bowsher, J., Maloney, J. P., \& Lillis, P. P. (1997). Social support: a conceptual analysis Journal of Advanced Nursing, 25(1), 95-100. https://doi.org/10.1046/j.1365-2648.1997.1997025095.x

Masten, A. S. (2014). Ordinary Magic: Resilience in Development The Guilford Press. https://books.google.com.br/books?id=xuQ-BAAAQBAJ

Migliorini, C., Callaway, L., Moore, S., \& Simpson, G. K. (2019). Family and TBI: An investigation using the Family Outcome Measure - FOM-40. . Brain Injury, 33(3), 282-290. https://doi.org/https://doi.org/10.1080/02699052.2018.1553307

Morais, N., Koller, S., \& Raffaelli, M. (2016). Inserção Ecológica na pesquisa sobre trajetórias de vida de adolescentes em situação de vulnerabilidade social: Identificando fatores de risco e proteção. In C. d. Psicólogo (Ed.), Inserção ecológica: um método de estudo do desenvolvimento humano. (pp. 65-91).

Rosa, E. M., Nascimento, C. R. R., Santos, A. P. d., Melo, C. R. d. S., \& Souza, M. R. d. (2016). Inserção ecológica em uma instituição de acolhimento para crianças no Espírito Santo. In N. Araujo de Morais, S. H. Koller, \& M. Raffaelli (Eds.), Inserção ecológica: um método de estudo do desenvolvimento humano (pp. 95-118). Casa do Psicólogo.

Rutter, M. (2012). Resilience as a dynamic concept. Development and Psychopathology, 24(2), 335-344. https://doi.org/10.1017/S0954579412000028 Seligman, M. E. P., \& Csikszentmihalyi, M. (2000). Positive psychology: An introduction American Psychologist, 55(1), 5-14. https://doi.org/10.1037/0003066X.55.1.5

Waters, L., White, M., \& Murray, S. (2012). Toward the creation of a positive institution The International Journal of Appreciative Inquiry, $14(2), 60-66$. http://hdl.handle.net/2440/124206

White, M. A., \& Murray, A. S. (2015). Building a positive institution In Evidence-based approaches in positive education (pp. 1-26). Springer.

World Health Organization, W. (2018). Global status report on road safety 2018: Summary https://apps.who.int/iris/bitstream/handle/10665/277370/WHONMH-NVI-18.20-eng.pdf

Yin, R. K. (2015). Estudo de Caso-: Planejamento e métodos. Bookman editora.

Yunes, M. A. M. (2015). Dimensões conceituais da resiliência e suas interfaces com risco e proteção In S. G. Murta, C. Leandro-França, K. Brito, \& L. Polejack (Eds.), Prevenção e promoção em saúde mental: Fundamentos, planejamento e estratégias de intervenção. (1 ed.). Synopisis. https://www.sinopsyseditora.com.br/livros/prevencao-e-promocao-em-saude-mental-fundamentos-planejamento-e-estrategias-de-intervencao-356

Yunes, M. A. M., \& Juliano, M. C. C. (2015). La importancia de las redes de apoyo en la promoción de la salud y resiliencia comunitaria. In E. Saforcada, J. C. Sarriera, \& J. Alfaro (Eds.), Salud comunitaria desde la perspectiva de sus protagonistas: la comunidad (Vol. Salud Comunitaria, pp. 213-232). Nuevos Tiempos.

Yunes, M. A. M., \& Szymanski, H. (2003). Crenças, sentimentos e percepções acerca da noção de resiliência em profissionais da saúde e da educação que atuam com famílias pobres Psicologia da Educação. Revista do Programa de Estudos Pós-Graduados em Educação. PUC SP(17). https://revistas.pucsp.br/psicoeduca/article/view/30846

Zappe, J. Z., Yunes, M. A. M., \& Dell’Aglio, D. D. (2015). Psicologia dos desastres e resiliência comunitária: reflexões sobre o incêndio da Boate Kiss em Santa Maria. In R. M. Coimbra N. A. M. (Eds.), A resiliencia em questões: perspectivas teóticas, pesquisa e intervenção. (pp. 215-229). Artmed. 